\title{
O Currículo de Matemática em revista: um editorial
}

\author{
Célia Maria Carolino Pires \\ Elenilton Vieira Godoy \\ Márcio Antonio da Silva \\ Vinício de Macedo Santos
}

Editores convidados

De modo paralelo à realização de um número crescente de estudos e pesquisas sobre "Currículos" na área de Educação, têm sido desenvolvidos também estudos similares sobre "Currículos de Matemática" no âmbito da Educação Matemática. A visibilidade, proporção e ênfases são diferentes, porém a aproximação de temáticas, focos de pesquisa e perspectivas teóricas entre as produções são evidentes, o que não poderia ser diferente dado que tanto as áreas quanto o campo temático são conexos.

Kilpatrick (1998) $)^{1}$ se refere às "mudanças curriculares" como uma das sete tendências temáticas na Educação Matemática mundial, durante a década de 1990. No entanto, os movimentos de pesquisas sobre currículos são relativamente instáveis. Internacionalmente, segundo Rico $(2013)^{2}$, a presença explícita de objetivos e interesses curriculares é reconhecida na maioria das pesquisas realizadas antes da Segunda Guerra Mundial e bastante comum nos trabalhos antes dos anos 70. A partir dessa data, a referência curricular não esteve mais presente ou deixou de ser uma prioridade nas investigações. Na opinião desse autor, nunca houve um grupo internacional estável dedicado a coordenar o trabalho de pesquisadores sobre o currículo de Matemática, ou que teve como um dos seus principais objetivos o intercâmbio de resultados de pesquisa sobre o currículo, como já aconteceu com os pesquisadores interessados na cognição em Matemática que constituiram The International Group for the

\footnotetext{
${ }^{1}$ KILPATRICK, J. Investigación em educación matemática: su historia y algunos temas de actualidad. In: KILPATRICK, J.; GÓMEZ, P.; RICO, L. Educación Matemática: Errores y dificultades de lós Estudiantes. Resolución de problemas. Evaluación. Historia. Bogotá: Universidad de lós Andes, 1998. p. 1-18.

${ }^{2}$ RICO, L. O que devemos pesquisar sobre currículos de Matemática? In: FÓRUM NACIONAL SOBRE CURRÍCULOS DE MATEMÁTICA: PESQUISAS E POLÍTICAS PÚBLICAS, 2., 2013, São Paulo. Anais... São Paulo: Zapt Editora, 2013, p. 9-19.
} 
Psychology of Mathematics Education (PME), os interessados na relação entre história e Educação Matemática, que formaram The International Study Group on the Relations between History and Pedagogy of Mathematics (HPM), ou pesquisadores envolvidos na investigação e fundamentos teóricos da Educação Matemática, que instituiram Theory of Mathematics Education (TME), entre outros. As investigações sobre o currículo, dentro e fora da Educação Matemática, sempre foram ligadas a um projeto e grupos internacionais foram formados em relação a estudos comparativos também internacionais. Essas limitações têm restringido o desenvolvimento de um grupo de pesquisa consolidado sobre o currículo de Matemática.

De certa maneira, aspectos relativos aos estudos e às práticas curriculares em Educação Matemática desenvolvidos nos diferentes países, como os destacados por Kilpatrick, podem ser identificados a partir do conjunto de temas e eixos de discussão definidos em congressos internacionais como, por exemplo, o ICME, no qual tem figurado o tema dos currículos de Matemática. O objetivo é configurar, de uma perspectiva internacional, um estado da arte relativo a determinado tema ou problema, com atenção voltada para as práticas de grupos e comunidades de pesquisas, para a produção de novos conhecimentos, às formas como os problemas são equacionados, às novas perspectivas e às questões emergentes. Relativamente aos currículos de Matemática, apresentamos, neste número, um levantamento dessa natureza em que, a despeito das diferenças de formas de pesquisar e de desenvolver currículos de Matemática e da existência de grupos envolvidos nessa tarefa, é preponderante o papel de organismos oficiais da educação na formulação e normatização de padrões curriculares e na sua implementação.

No Brasil, na área de Educação, o currículo é tema de diferentes grupos de investigação, como mostram os dados do diretório de grupos de pesquisas. Há 231 grupos registrados no Diretório dos Grupos de Pesquisa no Brasil (DGP). Na área de Educação Matemática, a presença do termo currículo nas nomeações dos grupos de pesquisa não é tão frequente. É possível conjecturar que, em grande parte das investigações na área de Educação Matemática, o currículo aparece em pesquisas com outros focos, contudo não é abordado como um objeto de investigação em si mesmo. Outro aspecto observável é o ainda pequeno diálogo entre tendências curriculares na área de Educação e na de Educação Matemática.

A área de Educação Matemática tem criado pouco espaço, nos congressos e periódicos realizados e publicados no Brasil, para o debate a respeito do currículo de Matemática, o que pode ser evidenciado pela baixa produção de estudos (dissertações e teses) sobre a temática. 
Consequentemente, há poucos grupos de pesquisas que tratam sobre o currículo da Matemática escolar e, por isso, mas não somente, o debate, quando ocorre, de um modo geral, restringe-se aos métodos de avaliação e transmissão do conhecimento matemático. Portanto, os estudos e investigações curriculares na área de Educação Matemática, quando ocorrem, têm privilegiado, sobremaneira, os currículos prescritivos organizados ao longo do século $\mathrm{XX}$, no Brasil, ora pela via histórica, ora pela via comparativa com documentos curriculares de outros países e/ou documentos nacionais de outras épocas. Há pouca ressonância dos estudos feitos no campo do currículo, na Educação Matemática.

Em nosso entendimento, a ausência de debate entre os estudos e pesquisas do campo do currículo com os estudos e pesquisas envolvendo a Matemática escolar é uma problemática de investigação bastante fértil, para os tempos presente e futuro, devido ao distanciamento entre as disciplinas escolares e as teorias mais atuais do currículo, principalmente, a partir do momento em que, por um lado, as discussões no campo do currículo passam a ser mais teóricas, sobretudo, por ser um campo de estudo, no Brasil, em fase de consolidação e, por outro, as discussões, no país, envolvendo a organização curricular da Matemática escolar são marcadas, fortemente, pela preocupação em articular os diferentes elementos que constituem a dimensão normativa do currículo, quais sejam o objetivo, o conteúdo matemático, a metodologia e a avaliação.

O debate sobre currículo e os estudos curriculares tendem a ganhar projeção e intensidade na atualidade seja pelas mudanças políticas e seus impactos na ordem local, nacional ou global bastante marcada por processos migratórios, por diásporas de povos e etnias, pela multi e interculturalidade e, consequentemente, por tensões e reações de várias ordens, entre elas, as que degeneram em intolerância; seja também pela exclusão social, pela tendência de universalização da educação básica e/ou ainda pelos resultados produzidos pelas inúmeras formas de avaliação em larga escala adotadas em diferentes países cumprindo a função reguladora, em vários casos unificadora, de sistemas educacionais diversos pela via curricular. Verifica-se a centralidade que hoje ocupam as questões curriculares no desenho e na implementação de políticas educacionais no Brasil, influenciando de modo incontestável as práticas pedagógicas, os processos de formação docente e de pesquisas na Universidade, especialmente a partir dos anos 90, com a publicação das diretrizes e parâmetros curriculares nacionais e regionais.

Nesse contexto, uma edição do $\boldsymbol{B O L E M A}$ que tematize o currículo da Matemática na Educação Básica, a partir de estudos comparados, estudos teóricos, entre outros, e que procure 
ampliar as dimensões abordadas, para além da dimensão normativa do currículo, mais frequentemente enfatizada, constitui-se instrumento de promoção do debate necessário e de aproximação entre pesquisadores, professores e futuros professores de Matemática da Educação Básica centrados nos aspectos práticos da organização curricular na escola e nos aspectos epistemológicos dos currículos de Matemática.

No mês de março de 2013 entramos em contato com o editor chefe do BOLEMA, Antonio Vicente Marafioti Garnica, perguntando sobre a possibilidade de publicar uma edição temática da revista sobre Currículo da Matemática escolar. Prontamente, Vicente se interessou pela ideia e, no final do mês de abril de 2013, iniciaram-se os trâmites para divulgação da chamada e envio dos artigos. O processo de submissão findou-se em julho de 2013.

Foram apresentados 22 artigos para avaliação que foi feita por um grupo de pareceristas ad hoc, distinto do conselho editorial da revista.

Foram selecionados 9 dos 22 artigos submetidos para a avaliação, considerando-se a pertinência dos mesmos em relação aos critérios destacados na chamada de artigos proposta sobre a temática do currículo, contando com a análise de dois pareceristas e consolidada pelos editores convidados.

Os textos selecionados para esta edição temática do $\boldsymbol{B O L E M A}$ mostram algumas das tendências investigadas em nossa comunidade, bem como trazem dados comparativos de vários países relativos às formas de produção e desenvolvimento curricular no âmbito do ensino de Matemática para a Educação Básica.

Dois artigos abordam questões de natureza conceitual sobre currículos e também sobre as investigações a respeito desse tema. O artigo "El Currículo de las Matemáticas Escolares y el Gobierno del Sujeto Moderno", das pesquisadoras Paola Valero e Gloria García, investigam o entendimento de como as práticas e discursos da educação matemática fabricam o sujeito racional, objetivo, universal que encarna o cidadão cosmopolita moderno.

$\mathrm{O}$ artigo "Currículo como Currere, como Complexidade, como Cosmologia, como Conversa e como Comunidade: contribuições teóricas pós-modernas para a reflexão sobre currículos de matemática no ensino médio", de Marcio Antonio da Silva, apresenta algumas contribuições de teorias curriculares pós-modernas, argumentando que é imprescindível discutir questões referentes à seleção e à organização curricular de temas matemáticos no ensino médio brasileiro.

Um artigo traz análises e reflexões sobre documentos curriculares colocando o foco nas prescrições: "Pesquisas e documentos curriculares no âmbito da Educação Matemática de 
Jovens e Adultos", de Gilberto Januário, Adriano Vargas Freitas e Kátia Lima apresenta resultados de investigação realizada sobre os currículos de Matemática no caso específico da Educação de Jovens e Adultos. Um artigo focaliza, especificamente, o currículo apresentado pelos materiais didáticos: "Livros didáticos e apostilas: o currículo de Matemática e a dualidade do Ensino Médio", de Aline Germano Fonseca e Denise Silva Vilela compara apostilas e livros didáticos de Matemática do Ensino Médio, enfocando, a partir da teoria crítica de currículo, conteúdos, sequências e objetivos de ensino descritos nestes materiais.

Quatro artigos tratam do currículo em sua apropriação pelos professores: (i) "A Transformação dos Textos dos Materiais Curriculares Educativos por Professores de Matemática: uma análise dos princípios presentes na prática pedagógica”, de Wagner Ribeiro Aguiar e Andreia Maria Pereira de Oliveira, discute como professores operam a recontextualização dos textos dos materiais curriculares educativos na prática pedagógica e quais princípios regulam a operacionalização da recontextualização; (ii) “Gestão do Currículo de Matemática sob Diferentes Profissionalidades", de Vanessa Moreira Crecci e Dario Fiorentini, analisa como professores de Matemática receberam e utilizaram o material enviado pela Secretaria de Educação do Estado de São Paulo (SEE-SP), no período de 2008/2009, no contexto do programa "São Paulo faz Escola"; (iii) "Revelações de Professores dos Três Primeiros Anos do Ensino Fundamental da Rede Municipal de São Paulo sobre o Currículo Prescrito e o Apresentado no Ensino de Matemática", de Janaina Pinheiro Vece e Edda Curi, investiga, com base nos estudos de Sacristán, a dimensão prescrita e apresentada do currículo de Matemática do Município de São Paulo, bem como identifica as percepções dos professores de $1^{\circ}$ e $3^{o}$ anos do Ensino Fundamental a respeito deste currículo; e (iv) "Construção do Currículo de Matemática: como os professores dos anos iniciais compreendem o que deve ser ensinado?”, de Marcelo Câmara dos Santos, Maria Isabel Ramalho Ortigão e Glauco da Silva Aguiar, busca compreender a relação do professor dos anos iniciais com os saberes a serem ensinados, tomando como base os Parâmetros Curriculares para a Educação Básica do Estado de Pernambuco, que descrevem as expectativas de aprendizagem.

Um artigo traz contribuições acerca da relação entre currículo e estudantes: "A Relação Família-Escola e a Prática do 'Dever de Casa' de Matemática: um estudo sobre seus tensionamentos”, de Gelsa Knijnik e Débora de Lima Velho Junges focaliza um aspecto da relação entre estudante e currículo, ao problematizar tensionamentos produzidos na relação família-escola mediante a prática do "dever de casa” de Matemática. 
O último artigo "Curriculum and the Role of Research: report of the ICME 12 Survey Team", apresenta uma análise feita a partir do conjunto de dados levantados por equipe de pesquisadores de diferentes países para o ICME-12 Survey Team (ST1): The relationship between rearch and curriculum design. O levantamento foi feito a partir de várias questões de pesquisa e foi organizado de modo a compor um painel comparativo sobre a produção curricular e sua normatização, o apoio aos professores e o papel dos livros didáticos e das tecnologias nas salas de aula. Fica evidente na análise desses que apenas em alguns países a pesquisa tem um papel importante na elaboração e acompanhamento do desenvolvimento do seu currículo de Matemática havendo uma grande variação entre os países quanto à implementação, mas com uma preponderância do papel do Estado nesse processo.

Por fỉm, manifestamos a satisfação de apresentar esse número temático do Bolema com parte da produção de pesquisadores brasileiros da área de Educação Matemática, cientes de que a diversidade de questões tratadas nos artigos revela o modo como as questões do currículo instigam esses pesquisadores e sinaliza o rumo que tomam seus estudos. Na falta de um panorama mais abrangente e completo, resultado de uma análise do estado da questão no plano internacional, optamos por apresentar alguns indícios do que foi possível reunir e veicular no ICME 12.

Gostaríamos de agradecer tanto a oportunidade dada pelo $\boldsymbol{B O L E M A}$, na figura do seu editor, Vicente Garnica, para discutir a temática do currículo que é pouco explorada nos eventos e periódicos da área de Educação Matemática, quanto aos revisores ad hoc ${ }^{3}$ que nos auxiliaram e, muito, em todo o processo.

\footnotetext{
${ }^{3}$ Os pesquisadores que atuaram como pareceristas ad hoc para esta edição estão dentre os pesquisadores incluídos na Nominata divulgada na edição de número 48, de abril deste ano, do BOLEMA.
} 